\title{
HACIA UNA POÉTICA DE LA TECNOLOGÍA PERIFÉRICA: POST-CYBERPUNK Y PICARESCA 2.0 EN SLEEP DEALER DE ALEX RIVERA
}

POR

\author{
Hernán Manuel García \\ Wayne State University
}

La revista Science Fiction Studies -siguiendo el concepto de "imaginative representations of globalization" de Suma Gupta-dedicó un número especial (Noviembre 2012) para explorar cómo la ciencia ficción contemporánea ofrece nuevos acercamientos entorno a la globalización. Aunque el estudio de la globalización parece un tema desgastado y agotado, el número especial de Science Fiction Studies es relevante y de suma importancia ya que explora otras posibilidades para el estudio de la globalización desde lo imaginativo y lo especulativo como formas de teorizar la globalización.

Con esta idea en mente, este trabajo ofrecerá un acercamiento a las redes globales, al ciberespacio y a las tecnologías digitales desde la mirada periférica de un campesino mexicano a punto de convertirse en cyborg y nøøb (hacker principiante). Para contextualizar esta idea, el trabajo se concentrará en analizar la cinta de Alex Rivera Sleep Dealer (2008) no como una película cyberpunk, sino como un ejemplo de la estética postcyberpunk que resulta más provechoso para abordar procesos culturales actuales acorde a las realidades de los países latinoamericanos en proceso integración a la era de la información a principios de siglo XXI. En este sentido, el trabajo argumentará que el personaje cyborg-hacker, de la película, con tecnología periférica e insipiente conocimiento y manejo de ella es un pícaro de la era de la información que ofrece un testimonio en versión 2.0 para compartir una realidad alterna de las tecnologías de la información y comunicación desde el subdesarrollo del Tercer Mundo.

De acuerdo con Danny J.Anderson, una gran parte de la expresión cultural mexicana de finales del siglo XX y principios del siglo XXI responde a las contradicciones sociales que surgieron después de la ratificación del Tratado de Libre Comercio de América del Norte entre Estados Unidos, Canadá y México en 1994 (27). A partir de este momento, surgen una infinidad de obras literarias que dan testimonio y que dialogan con el discurso neoliberal. Esta obras hacen hincapié en la presencia y los mecanismos de la economía global, el mercado libre y la libre circulación de mercancías en un momento en que la nación no estaba preparada para dicha transición, mostrando 
así los efectos negativos de la implementación de la agenda neoliberal en todas las facetas de la vida cotidiana en México.

En medio de la crisis económica y la promesa de la hiper-modernidad que nunca llega, entre la introducción de la Internet y la inestabilidad política durante la década de los noventas, una generación de escritores de ciencia ficción surgió de la clandestinidad para irrumpir en el campo literario mexicano. Estos escritores nutridos e influenciados desde la infancia por los medios y las tecnologías de la información y la comunicación, decidieron tomar -en palabras de Pepe Rojo- el lema punk del DIY (hágalo usted mismo) para explorar su presente y futuro a través de las herramientas de la ciencia ficción. Escritores como Gerardo Porcayo, Gerardo Sifuentes, José Luis Ramírez, José Luis Zárate y Bernardo Fernández reelaboraron los temas cyberpunk abordados por escritores anglosajones, diez años antes, y los adoptaron al Tercer Mundo enfocándose principalmente en la exploración y el análisis de los aspectos socio-psicológicos del uso de la tecnología como marcador de control y poder. Para estos autores, el futuro gobernado por corporaciones transnacionales se convierte en la principal referencia para desarrollar una temática pesimista y determinista en donde la tecnología no se representa como una posibilidad viable para generar un futuro prometedor.

De esta manera, la narrativa cyberpunk mexicana, en los años noventa, se consolida como una reacción contra los efectos negativos de la aplicación de la agenda neoliberal y la integración de México al modelo de la globalización. Bajo esta visión, la narrativa cyberpunk mostró el desgaste de los paradigmas nacionales y vislumbró los posibles efectos de subsistir como simples operadores o consumidores de tecnología. Imaginando, de esta manera, un futuro que describo como "pos-global". En la representación de este futuro "pos-global", el Estado mexicano se ha colapsado debido a la estrepitosa caída de la economía global, el grueso de la población subsiste paupérrimamente debido a las altas tasas de desempleo y las corporaciones transnacionales han ascendido al poder como las únicas entidades sobrevivientes y fortalecidas del fracaso del sistema neoliberal.

En gran medida, el ciberpunk mexicano es apocalíptico y no ofrece alternativas o soluciones a los problemas que se desarrollan en sus obras. Es un relato hiperrealista que imagina y teoriza sobre los problemas crónicos de desempleo, la injusticia social, y la crisis económica que experimentaba México a finales del siglo XX. Como regla general, los personajes de la versión literaria del cyberpunk mexicano experimentan situaciones de vida extremas que no pueden controlar o confrontar con éxito. Son personajes cuyo único y primordial objetivo consiste en sobrevivir, día a día, como sea posible en un mundo que no ofrece soluciones ni futuro para ellos.

Sin embargo, la narrativa cyberpunk en México se agotó hacia finales de los años noventa y López Castro afirma que a partir de 1998 se empiezan a gestar los primeros síntomas de tedio hacia este género de la ciencia ficción. Por una parte, 
esto correspondió a que varios de sus representantes habían alcanzado la madurez literaria, y en segunda instancia a que el cyberpunk cansó por sus temáticas repetitivas de desolación postindustrial y tramas policíacas que no ofrecían desafíos al lector. Aparecieron demasiados hackers e implantes biomecánicos bajo las mismas ciudades grises aplastadas por lluvia ácida, lo que le restó sorpresa y originalidad al género (177).

Sin lugar a dudas los noventa pertenecieron al cyberpunk en el sentido que el género se perfiló como punta de lanza para incursionar en el quehacer artístico del campo literario nacional. ${ }^{1}$ Sin embargo, hacia finales de la década de los noventas su reinado empezó a llegar a su fin. Por un lado, el cyberpunk sirvió como plataforma para que otros géneros se alimentaran de la raíz original, como el steampunk y el ribopunk, pero estas nuevas germinaciones no llegaron a tener larga vida (179). Por otro lado, los escritores representativos del cyberpunk, optaron por reinventarse y encontrar en diferentes géneros literarios otros espacios. Este ha sido el caso de Gerardo Porcayo que se inclinó por lo neogótico (Dolorosa, 1999), Gerardo Sifuentes se adhirió a las filas del avant-pop (Pilotos infernales, 2001), José Luis Zárate incursionó en temas clásicos de aventuras (La ruta del hielo y la sal, 1998), Pepe Rojo con su especialidad en medios masivos de comunicación buscó un realismo mediático (Punto cero, 2000) y Bernardo Fernández ha incursionado en la narrativa neopolicíaca (Tiempo de alacranes 2005).

En la actualidad, ha resurgido un interés académico por estudiar el cyberpunk mexicano por parte de una nueva generación de lectores y críticos que observan que las temáticas y problemáticas abordadas por los escritores cyberpunk siguen manteniéndose vigentes. Pepe Rojo ante este fenómeno, que pone de manifiesto cómo el cyberpunk a través de visión se adelantó a su época, explica que los escritores cyberpunk tuvieron suerte y acertaron en buena manera a las problemáticas que trataron en varias de sus obras ("Re: Saludos y consulta").

De entrada al siglo XXI, el cyberpunk en México -así como sucedió en la década de los ochentas en Estados Unidos- se extendió a otras expresiones artísticas. Particularmente, el cyberpunk fue absorbido y explotado por los medios masivos de comunicación que se encargaron de diseminarlo como un producto de consumo a principio del nuevo milenio. Un síntoma que sin lugar a dudas interpelaba a los mexicanos, a través del uso de las tecnologías de la información y la comunicación, a observarse como una nación dentro de la cartografía del ciberespacio. Horacio Moreno observa que la popularización masiva del cyberpunk y de sus temáticas suavizó el carácter contracultural del movimiento original y lo convirtió en un artículo comestible de moda (7).

Ignacio M. Sánchez Prado afirma que México ofrece un modelo peculiar para estudiar el impacto de los géneros literarios, como la ciencia ficción, en el campo literario nacional. Además en su artículo propone estudiar la ciencia ficción mexicana como una practica artística que ha sido integrada al campo literario nacional y no como una expresión de resistencia o marginalidad ("Ending the World with Words" 112). 
Un primer ejemplo de esta diseminación fue la circulación de la revista Complot internacional: Operación caos cultural que a través de sus temáticas contraculturales ofrecía información sobre los diferentes movimientos underground en México. La edición de agosto de 1997 fue dedicada a la ciencia ficción mexicana y en este número aparecieron los diseños de moda cyberpunk del reconocido artista conceptual Martín Rentería. La colección de prendas y accesorios de corte cyberpunk de Rentería habían sido reconocidos con premios internacionales tanto en la industria del diseño de modas como en la escena del performance conceptual. Sin embargo, en la edición de Complot internacional las piezas de Rentería fueron utilizadas como ornamento de decoración. La famosa actriz mexicana Claudia Ramírez fue la encargada de posar ante las cámaras vistiendo los atuendos cyberpunk de Rentería. Las vistosas y exóticas fotografías sólo sirvieron para decorar una frívola y simple entrevista al estilo de revista de celebridades, reduciendo el elemento cyberpunk de las piezas a la categoría de accesorio de moda.

Sería a través de las expresiones artísticas visuales independientes que el tratamiento de las temáticas originales del cyberpunk iban a ser reorganizadas y replanteadas para ofrecer nuevas propuestas y perspectivas. En este sentido, la película Sleep Dealer de Alex Rivera no se perfila como un cliché de las temáticas presentes en el cyberpunk clásico ${ }^{2}$ ya que propone una visión fresca y diferente de lo qué significa la experiencia humana en el cyberpunk. Esta característica perfila a Sleep Dealer como un ejemplo de un nuevo y repensado cyberpunk. Un género que transmutó y que en palabras de Lawrence Person se ha convertido en postcyberpunk. ${ }^{3}$

Sleep Dealer no es una representación desgastada del cyberpunkya que el escenario ha dejado de ser totalmente callejero y sus personajes han dejado de ser anti-héroes solitarios. La cinta enfatiza que un marco telúrico rural como campo de acción y la colaboración comunitaria como epicentro de cambio pueden combinarse con elementos pertenecientes a las representaciones de la cibercultura. En el postcyberpunk, la calle ha dejado de ser el lugar de espera de la caída final para los desposeídos o los desertores de las normas dominantes. El postcyberpunk replantea el concepto de lo urbano y se propone que la calle tiene otros caminos que lleva a otros lugares como a la salvación. También, en el postcyberpunk resurgen las representaciones de la familia, el trabajador

2 Según James Patrick Kelly y John Kessel las historias que: 1) ofrecen una perspectiva global del futuro, 2) representan tecnologías que transforman el cuerpo y la mente, 3) proponen actitudes subversivas que problematizan valores tradicionales o conocimiento ancestral y 4) cultivan "a crammed prose style that takes an often playful stance towards traditional science fiction tropes" son clichés instantáneos del cyberpunk escrito en la década de los ochentas (ix).

3 En 1991 Lawrence Person fue el primero en referirse al término postcyberpunk al describir la novela Snow Crash de Neal Stephenson. Después en 1998, Person escribió el artículo "Notes Towards a Postcyberpunk Manifiesto" donde se proponía el nacimiento del Postcyberpunk como una evolución del cyberpunk. Años más tarde James Patrick Kelly y John Kessel editan la antología Rewired: The PostCyberpunk Anthology (2007). 
y la comunidad y se deja de lado al clásico personaje hacker llevando a cabo misiones suicidas en solitario. En otras palabras, hay un resurgimiento de los valores humanos y no una nota determinista ya que el significado de lo humano siempre está en constante negociación.

Igualmente, el tratamiento de las tecnologías de la información y la comunicación adquieren un nuevo significado. Por ejemplo, la realidad virtual ya no se representa como una estrategia de escape, de trampa o refugio sino que en el postcyberpunk las tecnologías adquieren la connotación de herramientas para ser apropiadas por la sociedad civil.

Todas estas nuevas reconfiguraciones que propone el postcyberpunk encajan adecuadamente para explorar y mostrar cómo las acciones del hacker y el cyborg en el audiovisual postcyberpunk adhieren adecuadamente a lo que llamo "estética de la esperanza". Una metáfora que ayuda a cuestionar nociones de trabajo e identidad en la era de la información desde el Tercer Mundo. "La estética de la esperanza" no es común en la versión literaria del cyberpunk mexicano ${ }^{4}$ ya que sus protagonistas son productos desechables con caducidad que se enfrentan constantemente ante situaciones límites en donde se pone de manifiesto su nula capacidad de reacción y supervivencia. En cambio, en la versión postcyberpunk audiovisual los protagonistas no son devorados por las situaciones límites, sino que las adversidades a las que se enfrentan son sorteadas con ejercicio crítico y activismo social. En otras palabras, una "estética de la esperanza" nace desde el abatimiento y se convierte en un acto creativo que permite inventar algo - por más limitadas que sean las herramientas-a través del conocimiento, la asimilación personal, la experiencia y la cooperación para dar paso a un camino de salvación.

La mayoría de los protagonistas de la versión literaria del cyberpunk mexicano están emparentados con el protagonista de Sleep Dealer en el sentido que todos ellos son hackers y debido a su mediación con la tecnología encarnan una identidad cyborg. Sin embargo, el protagonista de Sleep Dealer forma parte de una estirpe de cyborgs distinta. Ésta se encuentra consciente de que su condición está ligada de forma imaginaria y literal a las tecnologías. Por ende, es un personaje que tiene presente su condición de desfavorecido y al mismo tiempo se encuentra consciente de sus limitadas herramientas, pero busca la mejor forma de hacer frente a sus circunstancias con los medios que tienen a la mano. Es un cyborg que no se encuentra esperando el trágico final, sino uno en búsqueda de la salvación personal y colectiva. Para Donna Haraway, este tipo de cyborg es:

4 Uno de los escasos ejemplos narrativos del cyberpunk mexicano que ofrece una "estética de la esperanza" es el relato "Las tres Fridas" de Gabriel Trujillo Muñoz que aparece en la antología editada por Gerardo Porcado El hombre en las dos puertas: Un tributo de la ciencia ficción mexicana a Philip K. Dick(2001). 
[...] una promesa ilegítima que puede conducir a la subversión [...] se sitúa decididamente del lado de la parcialidad, de la ironía, de la intimidad y de la perversidad. Es opositivo, utópico y en ninguna manera inocente. Al no estar estructurado por la polaridad de lo público y lo privado, define una polis tecnológica basada parcialmente en una revolución de las relaciones sociales. (256)

Por lo consiguiente, propongo que este personaje "bastardo" de la era de la información emprende, frente a su creador, una "contra-cyber-cultura" con el objetivo de cimentar un mundo mucho más justo y equitativo a través de la apropiación social de la tecnología para configurar una auténtica sociedad red. Bajo esta premisa se observarán las estrategias que utiliza el personaje principal de Sleep Dealer para confrontar el sistema que lo creó y así reclamar una identidad propia. En este sentido el personaje principal de Sleep Dealer se perfilará como un cyborg contestatario. Para Haraway esta estirpe de cyborgs "[...] son los hijos ilegítimos del militarismo y el capitalismo patriarcal" (256).

El protagonista de la película Sleep Dealer se llama Memo y vive con su familia en una zona rural de Oaxaca, México. Durante su tiempo libre es un ávido aprendiz de hacker que se entretiene jugando con su receptor casero de señales satelitales. En las noches, Memo se distrae escuchando conversaciones desde lugares lejanos que le permiten preguntarse e imaginarse cómo sería su vida si pudiera salir de Santa Ana del Río y poder vivir conectado al sistema global. En el pueblo de Memo, una compañía multinacional - con sede en San Diego, California-ha construido una represa y el agua se encuentra privatizada y bajo resguardo. ${ }^{5}$ Los lugareños tienen que pagar grandes sumas de dinero por unos cuantos litros del vital líquido. El problema para la familia de Memo surge cuando la agencia de seguridad, Del Río Security, que se encarga de patrullar virtualmente la represa, descubre el receptor satelital de Memo y malinterpreta su uso asignándole fines de interferencia terrorista. Acto seguido, la agencia de seguridad envía a un piloto conectado al ciberespacio que virtualmente conduce un Unmanned Aerial Vehicle (o mejor conocido como drone) para destruir cualquier plan del supuesto The Aqua Terrorist Insurgency en donde muere trágicamente el padre de Memo. Debido a esto, Memo tienen que salir del pueblo rumbo a Tijuana

La idea de presentar la privatización del agua no se encuentra lejos de la realidad. En el 2000 en Cochabamba, Bolivia, la compañía Bechtel, gracias a presiones del Banco Mundial, consiguió que el gobierno boliviano le otorgara la concesión para administrar, distribuir y vender el agua a la población de Cochabamba. Los precios por los servicios de Bechtel aumentaron estrepitosamente y la población se levantó para protestar los altos precios del agua. Este incidente se conoció como "La guerra del agua". Además de Sleep Dealer, otras obras que han alimentado su marco de referencia con este suceso son la novela El delirio de Turing (2003) de Edmundo Paz Soldán y la película También la lluvia (2010) dirigida por Icíar Bollaín. 
por seguridad y también para buscar un empleo en una maquiladora para el sustento de su familia que se ha quedado desamparada.

Es así que Memo llega a la ciudad fronteriza de Tijuana con el propósito de emprender el viaje "al otro lado" para buscar un trabajo, pero el espectador se encuentra con la sorpresa de que el proceso de cruzar la frontera y conseguir un trabajo en los Estados Unidos ha cambiado por completo. Memo aprende que todo el trabajo de mano de obra se realiza en info-maquiladoras mexicanas en donde los trabajadores se conectan a la red a través de "nodos" para operar robots a control remoto como una forma de trabajo a distancia barato para los países desarrollados. Memo recorre las calles aledañas a la línea fronteriza y consigue los servicios de un coyotek para que le realicen una cirugía callejera con el propósito de instalarle los "nodos" tan necesarios para poder conectarse y entrar a trabajar a la cyber-maquiladora Cybracero.

Desde mediados de los años noventa, Alex Rivera ha investigado exhaustivamente el origen, el desarrollo y los resultados del Programa Bracero. ${ }^{6}$ Su trabajo siempre ha explorado y repensado de una forma ingeniosa los conceptos del trabajo, la migración, la tecnología y la política laboral y cómo estos han evolucionado con los inmigrantes en Estados Unidos. En torno a este tema, ha producido cortometrajes que exploran el desarrollo de la relación y la política laboral entre México y Estados Unidos. Carlos Ulises Decena y Margaret Gray opinan que:

His first short film, the experimental Papapapá (U.S., 1995), is a playful meditation on the mobility and metamorphoses undergone by two migrants: the potato, first cultivated by the Incas in Peru and later incorporated into the U.S. diet, and Augusto Rivera, Alex's father. With a ribald sense of humor, Rivera suggests the convergence of his father and the potato in envisioning Augusto as a "Peruvian couch potato, eating potato chips and watching Spanish-language television." The humor of Rivera's work, and the bite of his critiques, can also be appreciated in Why Cybraceros? (U.S., 1997), which uses an original 1940s promotional film by the California Grower's Council titled Why Braceros? to recount the history of the bracero program in the United States and to present a dystopic futuristic revamping of this program that imports the labor, but not the workers, from Mexico to the United States. (131)

Alex Rivera ha explicado que concibió la idea para la trama de la película Sleep Dealer en 1997 después de leer, en Wired Magazine, un artículo sobre Telecommuting que profetizaba que en un futuro todas las personas podrían trabajar desde sus casas.

6 En esta vertiente, su trabajo cinematográfico se caracteriza por el uso experimental de la animación, el uso de material de archivo y de entrevista. Rivera combina todos estos materiales para crear un estilo que él mismo ha llamado "estética rascuache" con el objetivo de [...] "to raise questions about immigrant labor as a mobile commodity and the relationship of this commodity (and the bodies that perform it) to capital accumulation" (Decena y Gray 131). 
Rivera explica que viniendo de una familia de migrantes, la idea le parecía fenomenal e imaginó un mundo de Tele-commuting Immigrants en donde los inmigrantes a Estados Unidos, provenientes de América Latina, podrían quedarse en sus lugares de origen y ofrecer su trabajo (Guillén) a través de la red en una especie de "Dark American Dream [...] work without the workers" (Sleep Dealer).

Javier Echeverría al analizar el teletrabajo en el entorno del ciberespacio estima que el teletrabajo no sólo requiere de infraestructuras de conexión global o nacionales de la información, sino que también se necesita de redes locales -a las que denomina Intranets- $\mathrm{y}$ de redes domésticas -o pasillos de la información- que hay que crear y mantener en operación a las afueras del gran sistema (234). Las características que Echeverría identifica en torno al teletrabajo son sumamente necesarias para hablar de Sleep Dealer ya que la cinta no sólo hace referencia a la red global dominada y controlada por corporaciones transnacionales, sino que también mucha de la acción se lleva a cabo al nivel de una red local. En Sleep Dealer, la red local o Intranet es representada por la cultura fronteriza, por los estereotipos de Tijuana como ciudad de paso y de migrantes, por su leyenda negra y por su fama de "ciudad del futuro" con su gran industria maquiladora. En la cinta, Tijuana representa una Intranet, un espacio marginal del sistema, que se conecta a la infraestructura global a través del submundo del mercado negro, de sus servicios "turísticos" y la industria maquiladora. Por otro lado, las redes domésticas o "los pasillos de la información" están representados en la película por medio de la cultura del bar fronterizo y el submundo de la industria de la migración ilegal en donde coyoteks y sleep dealers trafican con información reciclada, con tecnología pirata y con técnicas callejeras que prometen llevar a un individuo al nuevo "Dark American Dream", al otro lado de la frontera digital para trabajar a distancia.

El personaje de Memo llegará a conocer este sistema desde sus entrañas ya que va a transitarlo desde el espacio rural, pasando por el espacio urbano hasta desembocar en el ciberespacio. Esto le permitirá conocer el enmarañado sistema de las redes para entender cómo él -un campesino aprendiz de hacker-y su pueblo rural en Oaxaca se encuentran íntimamente conectados a la infraestructura global. Memo va a recorrer y a entender el sistema experimentando en carne propia todas las peripecias, las dificultades y los sinsabores de transitar por todos los niveles del ciberespacio a través de su teletrabajo.

La narración de todos los eventos, en la película, corre a través de la propia voz de Memo. De esta forma, la historia se cuenta in extremis desde una posición en la que el personaje principal está contemplando los hechos de forma consciente y madura para ofrecer una versión pensada y acabada de su historia. Esto le permite hablar desde un punto de vista testimonial que se presenta durante la película a dos niveles. Por un lado, Memo cuenta su historia a través de una narración en voice-over ${ }^{7}$ que le permite

7 Brian Henderson opina que el voice-over es utilizado al principio de una película a través de un flashback $\mathrm{o}$ al final de una película para actuar como un puente entre el pasado y el presente. Henderson explica 
al espectador seguir, entender y adentrarse en la historia de forma lineal desde el punto de vista de un personaje que ya ha pasado por un proceso de transformación interior. En segundo lugar, Memo a través de una serie de flashbacks, le permite al espectador entrar a su mente para compartir sus recuerdos y sensaciones en determinados punto del pasado.

El juego entre estos dos aspectos técnicos en la película le permite al espectador tener la sensación de observar a un personaje en plena construcción y desarrollo. Por lo consiguiente, se puede argumentar que la película Sleep Dealer es una especie de coming-of-age-film en donde Memo transita y se enfrenta a los valores del nuevo orden de la sociedad de la información hasta convertirse en un Self-Made Hacker. Así, la película se concentra en presentar la transformación de Memo como aprendiz de hacker a hacker de profesión. De esta forma, la cinta va presentando cómo se transforma la vacía seducción que Memo siente por la tecnología hasta descubrir el potencial de darle un uso crítico y social.

La historia de Memo y su presentación en forma testimonial -y por ende autobiográfica y didáctica- contada desde una posición que denota un importante aprendizaje y una profunda madurez hacen recordar a los personajes de la novela picaresca. Esto se presta para proponer que el personaje de Memo se puede observar como un personaje de la novela picaresca y de la crónica testimonial que se desenvuelve en el ciberespacio. En este sentido, el personaje pícaro y testimonial que encarna Memo no sólo es un agente que observa y denuncia en forma de testigo sino que re-conceptualiza el acto de testimoniar ya que él no se limita a ser un testigo que documenta, sino que al final de la película es un agente que actúa.

Hablar de la película Sleep Dealer como un ejemplo de la tradición literaria picaresca pudiera resultar tal vez un poco problemático de acuerdo a la multiplicidad de definiciones y debido a que generalmente el género se adscribe a un contexto sociohistórico específico: el de la España entre los siglos XV y XVIII al borde de virar hacía la modernidad. Sin embargo, como lo expresa Claudio Guillén en "Towards a Definition of Picaresque", la novela picaresca también se encuentra extendida por el tiempo y el espacio, lo cual cubre otras épocas y otros países. Por lo tanto, se puede encontrar una producción artística que se vale del "mito picaresco" para tomar prestada la estructura narrativa y la presentación de la situación del protagonista para desarrollar una historia (252).

La película Sleep Dealer no solamente se encuentra emparentada con la novela picaresca por tomar prestada su estructura narrativa y sus motifs recurrentes, sino que la cinta de Rivera se inserta dentro de una serie de películas que fusionan la ciencia

que también es una herramienta funcional para unir cabos sueltos en la historia. Esta estrategia permite eliminar la necesidad de dramatizar eventos que podrían distraer al espectador (58-59). 
ficción y la tradición literaria picaresca. De acuerdo con Bruce Burningham, una de las películas que abrió este camino fue la cinta La naranja mecánica (1971) de Stanley Kubrick y después se sumaron Blade Runner (1982) de Ridley Scott, Johnny Mnemonic (1995) de Robert Longo, Trainspotting (1996) de Danny Boyle, Fight Club (1999) de David Fincher y la trilogía Matrix (1999-2003) de los hermanos Wachowski (35). ${ }^{8}$

Guillén al hablar de la caracterización del protagonista pícaro sugiere que por lo general es huérfano, que confronta las más básicas necesidades, que se debate ante el deshonor, que por sus circunstancias rompe lazos con su ciudad natal, que gusta de la soledad, que se vale por sí mismo en un ambiente que no es el suyo, que aprende forzosamente de sus experiencias, que siente el mundo como cruel y que busca nuevos lugares a donde ir (254).

El personaje de Sleep Dealer reúne varias de las características del pícaro que enlista Guillén. Sin embargo, uno de estos rasgos de la picaresca que resalta significativamente en la película es la genealogía problemática del protagonista. En la cinta, la familia de Memo se caracteriza por ser una familia extendida que mantiene una conexión íntima con la naturaleza. Es una familia unida, propietaria de tierras de cultivos, que trabaja en sus cosechas y que tiene sus propios medios tradicionales para subsistir. Sin embargo, este tipo de organización social representa la "barbarie" de un tiempo antiguo que no concuerda o no es afín con el híper-desarrollo de la era de la información.

En la película se plantea la idea de que una sociedad con esas características representa un foco rojo en el mapa geopolítico global que no se ha alineado y adherido al sistema imperante y por lo consiguiente podría causar una desestabilización. Por lo tanto, la familia de Memo es marginal y de un "dudoso linaje" para un sistema basado en la proliferación de la tecnología porque su lado sospechoso consiste en que viven del campo y de la naturaleza a las afueras de la autopista de la información. Son en sí, criaturas de otro tiempo que por medio de la agricultura viven resistiendo y confrontando al sistema. En este sentido, Sleep Dealer es afín con la novela picaresca ya que se presenta el carácter "delincuente", "deshonrroso" "marginal" y "clandestino" de Memo y su familia.

En la película, la muerte del padre de Memo simboliza el intento de desaparecer todo un sistema rural incompatible con el avance tecnológico. Es la metáfora perfecta que renueva el concepto de civilización y barbarie de Sarmiento ya que como lo observa Arthur Kroker "[...] la utopista digital no solamente se traga cuerpos sino sociedades enteras" (198).

8 Burningham, opina que este corpus de películas son "In fact, the rise of what came to be known as "cyberpunk" literature (in all its manifestations) amounts to little more tan a postmodern permutation of picaresque narrative under the influence of the punk movement of the 1970s and the "hacker" culture that emerged in the wake of the Internet revolution of the 1990s" (36). 
La muerte del padre de Memo o la falta de la figura paterna en el seno familiar también se perfila como una de las coyunturas de más importancia en el desarrollo de Memo como adulto ya que uno de los rasgos más importantes en el proceso del pícaro como personaje es la orfandad (Burningham 40). En este sentido, el protagonista tiene que sufrir una pérdida familiar para convertirse en pícaro. Burningham opina que:

The reason this moment of abandonment is so crucial in any picaresque narrative is that it marks the point at which the protagonist realizes he is entirely alone in the world. For, it is at this moment when alienation [...] becomes the catalyst for picaresque self-representation. It marks the point at which the narrator ceases to be a child and starts down a path that will eventually lead to his status not just as an adult but as a narrator as well. (43)

No se puede afirmar que en la película Memo sea un niño, pero sí se puede argumentar que es un adolescente con características pueriles en proceso de maduración. Esto lo demuestra una de las primeras escenas en donde aparece Memo jugando con su aparato receptor como si fuera un videojuego mientras a un lado de él se observa el libro Hacking para principiantes (Hacking for Dummies) de Ricardo Domínguez. ${ }^{9}$ En esta escena, el título del libro se presta para caricaturizar a Memo como "principiante" o reducirlo al nivel de niño que a manera de pasatiempo explora y se entretiene con las tecnologías de la información y comunicación. Este rasgo es sumamente importante en el desarrollo de Memo y se puede explicar a través de la importancia del juego como vehículo de aprendizaje.

Johan Huizinga en su famoso estudio Homo Ludens: A Study of the Play Element in Culture habla sobre la importancia del elemento del juego en la cultura y la sociedad para sugerir que el juego es una condición primordial y necesaria para el desarrollo de la cultura. Huizinga se vale del concepto "Teoría del juego" para subrayar que el juego "[...] constitutes a training of the young creature for the serious work that life will demand later" (2). En otras palabras, Memo encarna a un homo ludens que mediante el juego de aprendiz de hacker se prepara jugando y explorando para afrontar más tarde a la cyber-maquiladora por medio de dándole un uso social a la tecnología.

En este sentido, el desarrollo de Memo como usuario de tecnología - del juego, a la exploración hasta la apropiación de la tecnología- concuerda ampliamente con

\footnotetext{
9 Este es un claro homenaje a la primera entrega de la película Matrix (1999). Al igual que en la película de los hermanos Wachowski, en Sleep Dealer aparece un libro al inicio de la película que funciona como preámbulo del tono crítico bajo el cual se conducirá la película. En el caso de Matrix aparece el libro Simulacra y Simulation del crítico francés Jean Baudrillard y en cuanto a Sleep Dealer se observa el texto de Ricardo Domínguez Hacking para principiantes. Es interesante notar que ambos textos son apócrifos ya que el libro de Domínguez no existe y en Matrix el orden de los capítulos del libro de Baudrillard fue alterado.
} 
el concepto de "racionalización democrática" de la tecnología de Andrew Feenberg. El crítico canadiense introduce este concepto para describir la apropiación social de la tecnología que desafía los monopolios de producción, las estructuras de poder no democráticas y las barreras de la comunicación ("Tecnología para comunidades").

El libro Hacking para principiantes de Ricardo Domínguez, mencionado hace unos instantes, permite advertir que la historia contada por Memo oscilará por los contornos de la "racionalización democrática". Este detalle no solamente es útil para mostrar (como ya se ilustró anteriormente) el lado de aprendiz de Memo, sino también sirve para que un espectador enterado en la cibercultura y hacktivismo sospeche, desde el principio de la película, que el protagonista tomando como modelo el trabajo de Ricardo Domínguez, no será un hacker anti-heroico al estilo de la narrativa cyberpunk. Así, Hacking para principiantes es una sutil sugerencia de la subversión que llevará acabo un aprendis de hacker con tecnología periferica.

Para observar este rasgo es importante mencionar que Ricardo Domínguez es un famoso activista y reconocido académico que ha utilizado la tecnología para realizar acciones de desobediencia electrónica en la red. Su trabajo se caracteriza por ser una combinación entre el activismo político, el arte conceptual y la innovación tecnológica. Domínguez es fundador del colectivo The Electronic Disturbance Theater (EDT) que a mediados de la década de los noventas logró una importante notoriedad en la comunidad hacktivista internacional por brindar su apoyo al Ejercito Zapatista de Liberación Nacional (EZLN). ${ }^{10}$

Así, en las montañas de Chiapas, en 1994, se hicieron los primeros disparos de la guerra de la información. Los Zapatistas a pesar de no contar con electricidad y teléfono llevaron la revolución a la red lanzando una llamada a las armas a través del internet para que otras personas se unieran a ellos en su resistencia contra el imperialismo económico. Ricardo Domínguez y su EDT fueron los primeros en responder a la llamada (Hacktivistas).

${ }^{10}$ El EZLN, comúnmente conocido como "Zapatistas", es un grupo revolucionario ubicado en el estado de Chiapas que se levantó en armas el primero de enero de 1994, el mismo día en el que entra en vigor el tratado de libre comercio (TLC) entre Estados Unidos, Canadá y México. Desde entonces el grupo guerrillero ha tenido una guerra declarada contra el gobierno mexicano, aunque ésta principalmente ha sido defensiva contra las incursiones militares, paramilitares y corporativas en la región de Chiapas. La base de apoyo social Zapatista se encuentra integrada en su mayoría por la población rural indígena, pero también cuentan entre sus filas a simpatizantes y colaboradores de zonas urbanas, así como con el apoyo internacional. Al inicio del levantamiento Zapatista, el gobierno reaccionó con una ofensiva militar sobre los indígenas y desde entonces el EZLN se abstuvo de utilizar armas y adoptó una estrategia simbólica para atraer el interés y el apoyo nacional e internacional. De esta forma, el EZLN cambió su discurso de guerrilla militarizada, al estilo tradicional latinoamericano, por una contraofensiva de guerra informacional. 
Fue de esta manera como el EZLN empezó a gestar vínculos de colaboración con grupos que utilizaban estratégicamente tecnologías de la información y comunicación (Association for Progressive Communications), artistas digitales (The Electronic Disturbance Theater) y activistas en red (Peace Net) (Lizama, "El poder" 16). Estos grupos no sólo dieron al EZLN las primeras estrategias de comunicación y hacktivismo a nivel digital, sino que además sirvieron como pioneros para emprender acciones de contra-información y de desobediencia electrónica ante la información manipulada de los medios masivos de comunicación y de los boletines oficiales del Gobierno mexicano durante el sexenio del presidente Ernesto Zedillo (1994-2000) (4).

En las propias palabras de Ricardo Domínguez, el zapatista es aquel que puede adoptar en su corazón los gestos poéticos de la guerra de la información (Hacktivistas). Para ejemplificar esta idea, Domínguez relata una historia acontecida el 3 de enero del 2000 cuando:

los periódicos del mundo entero hablaron de que las fuerzas aéreas zapatistas habían atacado al ejercito mexicano. Nadie sospechaba que los zapatistas tuvieran aviones ni que fueran capaces de pilotearlos. Pero, si leías el artículo descubrías de pronto que esas fuerzas áreas zapatistas eran en realidad aviones de papel de diferentes colores con mensajes de paz en su interior. De modo que los soldados dispararon contra esos aviones de papel. Ahí, tenemos una representación simulada, un gesto que crea ese espacio mágico en el que existe una fuerza aérea zapatista. Porque lo que se trata de transmitir es lo que los zapatistas llaman guerra de la información. Una guerra de palabras y no palabras para hacer la guerra. (Hacktivistas)

Inspirado por las ideas zapatistas, el EDT -dirigido por Ricardo Domínguezutilizó la red para emprender manifestaciones virtuales para protestar los planes del Gobierno Federal mexicano de intensificar las acciones militares en Chiapas. Rodríguez al recordar la desimanación de su famoso Virtual Sit-In, vía correo electrónico, a favor del EZLN lo describe de esta forma:

In solidarity with the Zapatista movement we welcome all netsurfers with ideals of justice, freedom, solidarity and liberty within their hearts, to a virtual sit-in. On January 29, 1998 from 4:00 p.m. [...] to 5:00 p.m. (on the following five web sites, symbols of Mexican Neoliberalism):

Bolsa Mexicana de Valores: http://www.bmv.com.mx

Grupo Financiero Vital: http://www.bital.com.mx

Grupo Financiero Bancomer: http://www.bancomer.com.mx

Banco de México: http://www.banxico.org.mex

Banamex: http://www.banamex.com

Technical instructions: Connect with your browser to the above mentioned web sites and push the "reload" button several times for an hour (with an interval of a few seconds in between). ("Digital Zapatismo" 53) 
El gesto simbólico de la desobediencia electrónica llevada a cabo por el Virtual Sit-In correspondió a la necesidad de "[...] to move the gesture from a symbolic position to a direct action-effect" (54).

Regresando a la cinta Sleep Dealer, el despertar de Memo igualmente también se da desde una posición simbólica que trasciende a la acción directa. Para que Memo pudiese haber llegado más allá del simple consumo de la información tuvo que convertirse en un "usuario informacionalmente hábil". Esto significa "[...] aquel ciudadano que sabe de la información, de su valor, y la cruza con otros y crea sus propios datos" (Lizama "La internet").

Esta idea es útil para considerar que el hacker no es un ser solitario sino miembro de una comunidad que mediante el trabajo colectivo proporciona un bien común basado en el análisis y la cooperación. Manuel Castells al referirse a la cultura hacker manifiesta su importancia y trascendencia como una comunidad que ha sido pieza fundamental en el desarrollo de la innovación tecnológica ("Informacionalismo" 190). Asimismo, Castells se expresa de la cultura hacker como un colectivo con "[...] a shared belief in the power of computer networking, and determination to keep the technological power as a common good" (The Internet Galaxy 52). La película se nutre de la idea de una comunidad de acción en el sentido que Memo se da cuenta que por sí mismo no podrá llegar a cuestionar y confrontar de forma efectiva el poder que lo está subyugando desde el espacio laboral.

Hacía el final de la película, Memo llega a compartir su plan de acción con una persona que se encuentra interesada en ayudarlo desde que murió su padre. Es así que el piloto virtual que tuvo las órdenes directas de Del Río Security de atacar la casa de Memo y eliminar a su padre se siente obligado en ayudar a Memo en todo lo que sea necesario para que él recupere algo de lo que perdió. Memo y Rudy en la cinta representan una misma especie de trabajador, son, en otras palabras, miembros de una misma clase que ha sido dividida por el acceso a la tecnología. Ellos representan dos tipos de "node workers" que trabajan para un mismo sistema que los ha puesto en contra. La unión de fuerzas entre Memo y Rudy simboliza la creación de una nueva clase social informacionalmente hábil que se reconoce, que ha superado diferencias y que comparte información para un bien común. La asociación de Memo y Rudy simboliza un "hackeo colectivo".

En el final de la película Memo y Rudy han confabulado un plan que servirá para ayudar a la comunidad de Santa Ana del Río. Memo logra introducir a Rudy a su infomaquila para que por medio de sus nodos y sus credenciales como militar se conecte a su base aérea. De esta forma, Rudy tiene acceso para pilotear su drone con la intención de conducirlo hasta la comunidad de Oaxaca con la evidente intención de hacer estrellar la nave contra la represa para hacerla explotar. La escena es sumamente interesante y sugerente ya que más allá de sus efectos especiales no tiene la intensión 
de ser una representación de una secuencia típica del cine de ciencia ficción. Sino que el momento en que Rudy hace explotar la nave en la represa, la escena evoca un efecto relacionado con los "gestos simbólicos" referidos anteriormente por Ricardo Domínguez.

Al principio de la película, el papá de Memo se encuentra mirando la represa y le explica a Memo el significado y los estragos que la construcción ha causado para la comunidad. Acto seguido, en una mueca de enfado, coraje e impotencia, el papá de Memo lanza una piedra que no causa ningún daño al estrellarse en el gigantesco bloque de concreto y que rueda sin fuerza hacia el precipicio.

En el desenlace de la película, durante la explosión que causa Rudy al hacer estrellar el drone en la represa, se intercala la secuencia del padre de Memo lanzando la piedra. El efecto del montaje de las dos secuencias va creando la ilusión de la piedra y el drone siguiendo la misma trayectoria de forma simultánea hasta coincidir en el mismo punto de impacto que causa la explosión. No me quiero referir a esta secuencia como una técnica de manipulación de imágenes, sino que prefiero proponerla como una metáfora de un gesto simbólico que Ricardo Domínguez ha bautizado como “Tecnología Maya”. Domínguez para referirse y explicar esta tecnología periférica del Tercer Mundo describe una historia relatada por el Sub Comandante Marcos del EZLN:

Hola. Bienvenidos, hermanos y hermanas. Welcome sisters and brothers, I'm going to tell you a little story, una pequeña historia: Pedrito (a Tojolabal, two and a half years old, born during the first Intergalactic) is playing with a little car with no wheels or body. In fact, it appears to me that what Pedrito is playing with is a piece of that wood they call "cork", but he has told me very decisively that it is a little car and that it is going to Margaritas to pick up passengers. It is a gray and cold January morning and we are passing through this village which is today electing the delegates (one man and one woman) who will be sent to the March meeting. The village is in assembly when a Commander-type plane, blue and yellow, from the Army Rainbow Task Force and a pinto helicopter from the Mexican Air Force, begin a series of low over flights above the community. The assembly does not stop; instead those who are speaking merely raise their voices. Pedrito is fed up with having the artillery aircraft above him, and he goes, fiercely, in search of a stick inside his hut. Pedrito comes out of his house with a piece of wood, and he angrily declares that "I'm going to hit the airplane because it's bothering me a lot." I smile to myself at the child's ingenuousness. The plane makes a pass over Pedrito's hut, and he raises the stick and waves it furiously at the war plane. The plane then changes its course and leaves in the direction of its base. Pedrito says "There now" and starts playing once more with his piece of cork, pardon, with his little car. The Sea and I look at each other in silence. We slowly move towards the stick which Pedrito left behind, and we pick it up carefully. We analyze it in great detail. "It's a stick," I say. "It is," the Sea says. Without saying anything else, we take it with us. We run into Tacho as we're leaving. "And that?" he asks, pointing to Pedrito's stick which we had taken. "Mayan technology," the Sea responds. Trying to remember what Pedrito did I swing at the air with the stick. Suddenly the helicopter 
turned into a useless tin vulture, and the sky became golden and the clouds floated by like marzipan. Muchas gracias, I hope you enjoyed the story. (citado en Fusco "Electronic Disturbance")

La referencia anterior permite argumentar que el padre de Memo al lanzar la piedra, de ninguna manera realiza un aspaviento insignificante o ingenuo, sino un acto performático y poético de resistencia que queda suspendido en el tiempo esperando su ejecución final. En el desenlace de la cinta Memo llega a entender el valor metafórico del acto de su padre y conjugando esta idea con su apropiación de la tecnología lleva a cabo el gesto poético de guerra simbólica que le permite crear espacios de inversión, intervención, cooperación y acción con el fin de mostrar al mundo la lucha de su comunidad.

La película, Sleep Dealer muestra cómo una corporación transnacional intenta utilizar los mecanismos de las estructuras económicas y tecnológicas a escala global como una simulación futurista de los posibles mapas geopolíticos y sus interconexiones. La historia de Memo, por una parte, relata cómo la simulación llevada a cabo por una corporación eventualmente fracasa en su propósito de establecer una cartografía neocolonial de control de los recursos naturales. Sin embargo, lo que sobresale en la cinta no es el fracaso y la imposibilidad corporativa sino cómo la combinación de las características del personaje pícaro, el grado testimonial en la narración, los gestos poéticos y simbólicos se convierten en la herramienta perfecta para generar la toma de conciencia, el activismo y la catarsis final desde una acercamiento imaginativo y especulativo.

En este sentido, la película no ofrece un análisis de la globalización desde una perspectiva real o precisa de las condiciones y consecuencias de las interconexiones globales. Al contrario, la cinta por medio del postcyberpunk contribuye a la teorización de la globalización desde un acercamiento impresionista y probable del futuro donde la esperanza de acción existe. En este sentido, el discurso de Sleep Dealer lleva al espectador a observar cómo un régimen de control global puede ser resistido y confrontado con éxito por agentes locales y autóctonos. La película bajo el lente postcyberpunk muestra cómo la ciencia ficción contemporánea o poscolonial latinoamericana ofrece una crítica del imperio del capitalismo tardío. A través de lo imaginativo, Sleep Dealer propone examinar las condiciones reales e históricas de injusticia y desigualdad en América Latina llevadas a cabo por la expansión capitalista del dominio occidental.

Así mismo, la cinta por medio de su personaje pícaro y bajo un tono testimonial propone nuevas alternativas para crear utopías de solidaridad e interconexión global desde prácticas culturales tradicionales latinoamericanas como lo son lo picaresco y el testimonio. Por ende, el personaje de Memo es la metáfora perfecta de la memoria colonial que a través de lo alegórico introduce la idea de que las comunidades locales o autóctonas poscoloniales necesitan tener su propia agencia con el objetivo de 
proclamar su propia auto-representación durante la era de la información. Por medio de la ciencia ficción, la película entra al discurso poscolonial para mostrar cómo el personaje de Memo y su comunidad, de raíz indígena, enfrentan a la globalización con expresiones subalternas.

\section{BiBLIOGRAFÍA}

Anderson, Danny J. "El futuro neoliberal y la utopía perdida en Lejos del paraíso de Sandro Cohen". Symposium 61/1 (2007): 27-42.

Burningham, Bruce R. Tilting Cervantes: Baroque Reflections on Postmodern Culture. Nashville: Vanderbilt UP, 2008.

Castells, Manuel. "Informacionalismo y la sociedad red". La ética del hacker y el espiritu de la era de la información. Pekka Himanen, ed. Barcelona: Ediciones Destino, 2001. 169-91.

The Internet Galaxy: Reflections on the Internet, Business, and Society. Oxford: Oxford UP, 2001.

Decena, Carlos Ulises y Margaret Gray. "Putting Transnationalism to Work: An Interview with Filmmaker Alex Rivera". Social Text 24/3 (2006): 131-38.

Dominguez, Ricardo. "Digital Zapatismo". Ars Electronica 98: Info War. Linz, Austria: Arts Electronic Center, 1998. 53-5.

Echeverría, Javier. Los señores del aire: Telepolis y el tercer entorno. Barcelona: Ediciones Destino, 1999.

Freenberg, Andrew. "Tecnología para comunidades y racionalización democrática". [en.medi@+enredandos].<https://www.sfu.ca/ãndrewf/enredo2.html>. 15 dic. 2000.

Fusco, Coco. "Electronic Disturbance: Ricardo Dominguez Interviewed". Subsol. 1 enero 1999. <http://subsol.c3.hu/subsol_2/contributors2/domingueztext2.html>. 20 abril 2011.

Guillén, Claudio. "Toward a definition of Picaresque". Proceedings of the III Congress of the International Comparative Literature Association. The Hague: Mouton, 1962. 252-66.

Guillén, Michael. "Q\&A: Alex Rivera, 'Sleep Dealer"'. San Francisco Film Society. 14 mayo 2008. <http://sf360.linkingarts.com/features/qa-alex-rivera-sleepdealer>. 20 abril 2011.

Gupta, Suman. Globalization and Literature. Cambridge: Polity Press, 2009.

Haraway, Donna. Ciencia, cyborgs y mujeres: La reinvención de la naturaleza. Madrid: Ediciones Cátedra, 1995.

Henderson, Brian. "Tense, Mood, and Voice in Film: (Notes After Genette)". Film Quarterly: Forty Years, a Selection. Berkeley: U of California P, 1999. 54-75. 
Huizinga, Johan. Homo Ludens: A Study of the Play-Element in Culture. Boston: Beacon Press, 1955.

Kelly, James P. y John Kessel. Rewired: The Post-Cyberpunk Anthology. San Francisco: Tachyon Publications, 2007.

Kroker, Arthur. "Capitalismo virtual". Tecnociencia y cibercultura: la interrelación entre cultura, tecnología y ciencia. Stanley Aronowitz, ed. Buenos Aires: Paidós, 1998.

Lizama, Jorge Alberto. "El poder de las redes sociales: activismo vs páginas web del gobierno mexicano". La cultura del espectáculo y el escándalo: los medios en la sociedad actual. Nery Córdova, coord. México: Universidad Autónoma de Sinaloa, 2007. 3-20.

"La Internet, potencialmente socializadora: Alberto Lizama". La Jornada. 16 oct. $2007 .<$ http://jornada.unam.mx/2007/1/16/index. php?section+espectaculos\&article=a10n1esp.>. 20 abril 2011.

López Castro, Ramón. Expedición a la ciencia ficción mexicana. México: Lectorum, 2001.

Moreno, Horacio. Cyberpunk: más allá de Matrix. Barcelona: Circulo Latino, 2003. Paz Soldán, Edmundo. El delirio de Turing. La Paz: Alfaguara, 2003.

Rojo, Pepe. "Re: Saludos y consulta”. Email to Hernán García. August 22, 2009.

Sánchez Prado, Ignacio. "Ending the World with Words: Bernardo Fernández (BEF) and the Institutionalization of Science Fiction in Mexico." Latin American Science Fiction: Theory and Practice. Nueva York: Palgrave Macmillan, 2012.

Sleep Dealer. Alex Rivera, dir. Los Angeles: Maya Entertaiment, 2009.

También la lluvia. Icíar Bollaín, dir. Chatsworth, California: Image Entertaiment, 2012.

Trujillo Muñoz, Gabriel. "Las tres Fridas". El hombre en las dos puertas: un tributo de la ciencia ficción mexicana a Philip K. Dick. Comp. Gerardo Porcayo, comp. México: Lectorum, 2000. 231-52. 